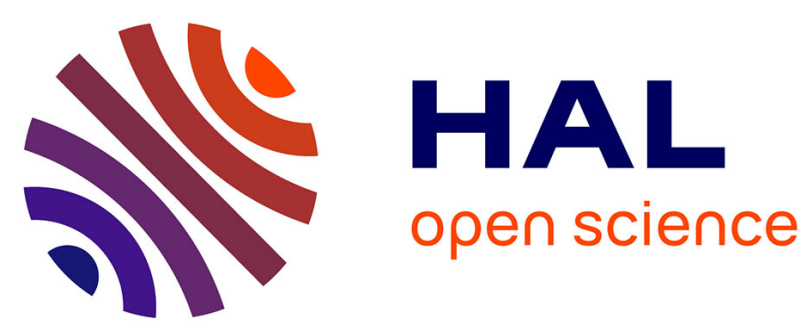

\title{
Burden of severe spondyloarthritis in France: A nationwide assessment of prevalence, associated comorbidities and cost
}

Pascal Claudepierre, Francis Fagnani, Gabrielle Cukierman, Thibault de Chalus, Jean-Michel Joubert, Caroline Laurendeau, Julie Gourmelen, Maxime Breban

\section{To cite this version:}

Pascal Claudepierre, Francis Fagnani, Gabrielle Cukierman, Thibault de Chalus, Jean-Michel Joubert, et al.. Burden of severe spondyloarthritis in France: A nationwide assessment of prevalence, associated comorbidities and cost. Joint Bone Spine, 2019, 86, pp.69 - 75. 10.1016/j.jbspin.2018.04.003 . hal03484641

\author{
HAL Id: hal-03484641 \\ https://hal.science/hal-03484641
}

Submitted on 20 Dec 2021

HAL is a multi-disciplinary open access archive for the deposit and dissemination of scientific research documents, whether they are published or not. The documents may come from teaching and research institutions in France or abroad, or from public or private research centers.
L'archive ouverte pluridisciplinaire HAL, est destinée au dépôt et à la diffusion de documents scientifiques de niveau recherche, publiés ou non, émanant des établissements d'enseignement et de recherche français ou étrangers, des laboratoires publics ou privés.

\section{(ㄷ)(1) $\$$}

Distributed under a Creative Commons Attribution - NonCommerciall 4.0 International 


\section{Burden of severe spondyloarthritis in France:}

\section{A nationwide assessment of prevalence, associated comorbidities and cost}

Pascal Claudepierre, ${ }^{a}$ Francis Fagnani, ${ }^{b}$ Gabrielle Cukierman, ${ }^{c}$ Thibault de Chalus, ${ }^{c}$ JeanMichel Joubert, ${ }^{c}$ Caroline Laurendeau, ${ }^{b}$ Julie Gourmelen, ${ }^{d}$ and Maxime Breban ${ }^{\text {e,f,g }}$

${ }^{a}$ AP-HP, Henri Mondor Hospital, Rheumatology Department, and Université Paris Est Créteil, EA 7379 - EpidermE, 94010, Créteil, France

${ }^{b}$ Cemka-Eval, 92340 Bourg-la-Reine, France

'UCB, 92700 Colombes, France

dUMS 011 - Inserm - UVSQ, 94807 Villejuif, France

eAP-HP, Ambroise-Paré hospital, Rheumatology Department, 92100 Boulogne, France

fUMR 1173 Inserm/University of Versailles-Saint-Quentin-en -Yvelines, 78180 Montigny-leBretonneux, France

gUniversité Paris Descartes, Sorbonne Paris Cité, Laboratoire d’Excellence Inflamex, 75006 Paris, France

\section{Author for correspondence:}

Pascal Claudepierre

Rheumatology Department, Hôpital Henri Mondor, 51, Avenue Mar de Lattre de Tassigny, 94000 Créteil, France

Tel.: +33.1.49.81.47.04

Email: pascal.claudepierre@aphp.fr 


\begin{abstract}
Objectives: To estimate the number of patients with severe spondyloarthritis $(\mathrm{SpA})$ in France, describe their comorbidities, and document and value their healthcare resource consumption.
\end{abstract}

Methods: Data were retrieved from an insurance claims database covering a 1/97 random sample of the French population. All patients benefiting from full insurance coverage ("ALD") for severe SpA in 2012 (including cases with structural damage and/or frequent flares) were identified, together with a control group frequency-matched by age and gender. Severe comorbidities were documented through ALD categories. Healthcare resource consumption was documented and valued from the payer's perspective. Rates of comorbidities and costs were compared in SpA patients versus controls using non-parametric testing.

Results: Overall, 827 patients with ALD status for severe SpA were identified (control group: $n=2,481$ ), corresponding to a prevalence rate of $0.18 \%[0.17-0.19]$ for SpA with ALD in the general population. Severe comorbidities more frequent in patients with $\mathrm{SpA}$ than in controls included inflammatory bowel disorders (odds ratio: 15.0 [6.2-36.2]), hypertension (2.5 [1.6-3.9]), atrial fibrillation (4.3 [1.9-9.6]) and major depressive disorder (2.1 [1.3-3.6]). Mean per capita annual direct healthcare expenditure was 3.6 [3.2-4.1]-fold higher in SpA patients $(€ 6,122[€ 5,838-€ 6,406])$ than in controls $(€ 1,682[€ 1,566-€ 1,798])$. Extrapolating to all patients in France, total healthcare cost attributable to severe SpA patients was $€ 391$ [€355-€426] million, with medication accounting for $53.8 \%$ of this cost.

Conclusions: The burden of severe SpA in France is substantial, due to the high prevalence, high direct costs, and associated comorbidities. 
Keywords : spondyloarthritis; Échantillon généraliste des bénéficiaires; Disease burden; Direct costs 


\section{Introduction}

Spondyloarthritis $(\mathrm{SpA})$ represents a group of chronic inflammatory disorders of the joint that predominantly affect the axial skeleton (1). The Assessment of SpondyloArthritis international Society (ASAS) classification criteria separate SpA into axial and peripheral SpA, based on the most prominent feature $(2,3) . \mathrm{SpA}$ worldwide prevalence has been estimated at between $0.20 \%$ and $1.61 \%$ (4). In France, two national surveys investigating the prevalence of SpA in the general population reported prevalence rates of $0.30 \%$ (5) and $0.43 \%$ (6). However, both the course and burden of $\mathrm{SpA}$ are very variable with respect to severity, and these studies provided no information on the frequency of severe forms of the disease.

Patients with SpA are suspected to be at increased risk of certain comorbidities compared to the general population (7), which may complicate management and lead to increased mortality (8). In particular, certain cardiovascular disorders, gastroduodenal ulcers and osteoporosis are frequently observed in SpA patients (7, 9-11). However, previous surveys that addressed these issues had limitations, particularly relating to representativeness, study sample size and lack of control groups.

Given that $\mathrm{SpA}$ is a chronic condition with an onset generally in young adulthood, the economic burden of SpA is significant, both in terms of direct medical costs and indirect costs associated with lost productivity $(12,13)$. However, many of the available economic studies predate the introduction of biological disease-modifying anti-rheumatic drugs (bDMARDs) (14-17). bDMARDs have ameliorated the functional status of the patient, thereby potentially reducing indirect costs, but they have also inflated direct medical costs attributable to medication. In France, the only available comprehensive economic data on SpA date from twenty years ago (14), although two subsequent micro-costing studies have 
focussed on specific patient groups $(18,19)$. More recent information is needed, specifically for patients with severe disease, who are expected to have higher healthcare costs.

The French insurance claims database "Echantillon Généraliste des Bénéficiaires" (EGB) enables epidemiological and economic information to be collected from a large sample of individuals who are fully representative of all health insurance beneficiaries in the country (20). The objective of this study was to estimate the number of patients with severe SpA, according to the currently accepted definition of the French health authorities (i.e. eligible for full coverage of all relevant medical expenses), to describe their comorbidities and to value their consumption of healthcare resources, using the EGB database.

\section{Methods}

This was a retrospective analysis of a cohort of patients with severe SpA identified in a French national health insurance claims database in 2012.

\subsection{The EGB database}

The EGB database is a random representative sample of $1 / 97$ of all individuals covered by three principal French public health insurance funds (21), which insure around $95 \%$ of the French population. The database contains anonymized data on around 600,000 individuals. Patients presenting with a restricted number of severe, costly, chronic diseases - including severe SpA, as defined by the French health authorities (Table 1) - are eligible for full coverage of all relevant medical expenses ("Affection de Longue Durée" [ALD] status) for a period of 5 years, which is renewable if clinically justified. Patients may benefit from an ALD status for multiple conditions. The thirty diseases entitling patients to ALD status are listed by the public health insurance funds, defined by International Classification of Diseases $10^{\text {th }}$ 
Revision (ICD-10) diagnostic codes (22). Patients with any of these diseases can be identified in the EGB database through the ICD-10 code associated with ALD status.

\subsection{Study population}

A cohort of all adult ( $>18$ years) patients with severe SpA documented in the EGB database on $1^{\text {st }}$ January 2012 was identified through their current ALD status associated with ICD-10 code M45 (ankylosing spondylitis and other $\mathrm{SpA}$ ) at this index date. For the purposes of this ALD eligibility, SpA is defined as severe if the patient fulfils at least one of the three criteria listed in the ALD guidelines published by the French health authorities (Table 1) (23). This population was considered as the prevalent population. An incident population of all patients becoming eligible for ALD status for SpA for the first time during the calendar year 2012 was also identified by excluding any patients with SpA ALD status prior to the index date. The population that was considered in the prevalence, costing and comorbidity analysis was composed of the total prevalent and incident population.

A control cohort was identified to estimate the relative risk (RR) of comorbidities in patients with SpA and the incremental costs attributable to SpA. To construct this control group, we used a stratified sampling approach consisting of distributing the SpA cases to exclusive sub-groups defined by age group and gender. We then identified controls for each sub-group by randomly selecting individuals without SpA from the database (3 control cases for each sub-group SpA case). 


\subsection{Data extraction and analysis}

\subsubsection{Prevalence and incidence rates of SpA}

Prevalence rates by age and gender were calculated by dividing the number of severe SpA patients categorised by age and gender by the total number of beneficiaries in the same group present in the EGB database. These rates were then applied to the total adult French population using national census data to estimate an adjusted national rate and the absolute number of cases (24). As mortality was quite low a similar approach was taken to calculate the incidence rates by age and gender and to obtain an adjusted national figure.

\section{$\underline{\text { 2.3.2 Comorbidities }}$}

All severe comorbidities associated with an ALD status during the calendar year 2012 were documented. We focussed the analysis on extra-articular manifestations of SpA (inflammatory bowel disorders $(25,26)$ ) and comorbidities with a suspected relationship to SpA (diabetes (27), cardiovascular disease (5), depressive disorders $(28,29)$ and cancer $(30)$ ).

\subsubsection{Healthcare resource consumption}

The database does not allow healthcare consumption to be ascribed to a specific diagnosis, with the exception of acute care hospitalisation. Data on the type and amount of healthcare resources consumed for all causes were extracted from the EGB database for the period from $1^{\text {st }}$ January to $31^{\text {st }}$ December 2012 . These covered all healthcare utilization, including hospitalisations, community care, medication delivery and laboratory tests.

\section{$\underline{2.3 .4 \text { Cost analysis }}$}

Direct medical costs were estimated from a payer (public health insurance) perspective for the calendar year 2012, using official French national tariffs. All items of healthcare consumption eligible for reimbursement and their associated costs were assessed. Hospital 
visits were valued according to standard tariffs applied to each type of hospital visit on the basis of a disease-related group (DRG) code. These represent an aggregate of all care services, including medication, expected to be used during the stay, each service being assigned a standard unit cost. Documented medication includes all medication dispensed in community care and intravenous biological agents administered in hospitals. Other drugs administered during inpatient stays were not documented separately as their cost is included in the DRG-based hospitalisation tariff. Medications of particular interest for patients with SpA were specifically identified from the EGB database. These included nonsteroidal anti-inflammatory drugs (NSAIDs), analgesics, glucocorticoids, and DMARDs. Conventional synthetic DMARDs (csDMARDs) identified included methotrexate, sulfasalazine, leflunomide, hydroxychloroquine, gold salts and immunosuppressant drugs. bDMARDS included all drugs approved for the treatment of SpA in France in 2012 (etanercept, adalimumab, infliximab, anakinra, tocilizumab, rituximab and abatacept). Costs were reported in 2012 Euros and are not adjusted for inflation.

Individual annual costs were extrapolated to national aggregate figures by using national census data.

\subsection{Statistical analysis}

Continuous data are presented as mean values \pm standard deviation or as median values, and categorical data as frequency counts and percentages with their $95 \%$ confidence intervals $(\mathrm{Cl})$. The occurrence of comorbidities in patients with SpA was compared to the control group using non-parametric Mann-Whitney tests as our sampling method did not use any individual matching. Other categorical data were compared using the $\chi^{2}$ test. All reported $p$-values and confidence intervals can only be interpreted in an exploratory 
manner, i.e., are nominal. All statistical analyses were performed using SAS $^{\odot}$ software Version 9.2 (Cary, USA).

\subsection{Ethical considerations}

Since this study was a retrospective analysis of an anonymised database and had no influence on patient care, ethics committee approval was not required. Access to the EGB database has been authorised for INSERM Unit U1018-UVSQ (Julie Gourmelen).

\subsection{Role of the funding source}

This work was supported by UCB Pharma, S.A.

\section{Results}

\subsection{Prevalence and incidence}

Of the 470,326 adults present in the EGB database in 2012,827 patients with ALD status for severe SpA were documented at least once. This corresponds to a crude prevalence rate of $0.18 \%$ [ $95 \% \mathrm{Cl}: 0.17-0.19]$. Prevalence rates varied with age and gender, with a higher overall prevalence in men $(0.20 \%[0.18 \%-0.22 \%]$ versus $0.15 \%[0.14 \%-0.17 \%]$ in women; $p<0.0001$, Figure 1). Prevalence increased with age until around fifty years old. Prevalence rates were lower in older patients, with the decrease occurring earlier in women than in men. Lower prevalence rates in women compared to men were only apparent in older age groups.

Of the 827 patients with ALD status for severe SpA, 762 were included in the database prior to $1^{\text {st }}$ January 2012 and were considered as the prevalent population at study entry. The mean age of the prevalent population was $50.4 \pm 14.3$ years and $57.3 \%$ [95\% $\mathrm{Cl}: 53.8 \%-$ $60.8 \%$ ] of them were men. They had benefited from ALD status for SpA for a mean $9.7 \pm 7.8$ 
years. The remaining 65 patients acquired ALD status for SpA during 2012 and were considered the incident population, corresponding to an annual incidence rate of 1.4 cases $/ 10,000$ persons. The incident population mean age was $42.7 \pm 11.7$ years and $38.5 \%$ [27.6\%-50.6\%] were men $(N=25)$. The observed gender ratio for incident and prevalent cases was different $(p=0.003)$.

\subsection{Mortality}

Mortality was similar in the SpA group (3/827 deaths) to that in the control group (11/2481 deaths; OR: 0.8 [0.2-2.9]; $p=0.76)$.

\subsection{Extra-articular manifestations and comorbidities}

Overall, 239 patients with ALD status for severe SpA (28.9\% [25.9-32.1]) also qualified for ALD status for at least one other condition. This proportion was higher than in the control group (18.8\% [17.3-20.4]; $p=0.0003)$. The most frequent comorbidities were diabetes $(6.2 \%$ [4.7-8.0]), hypertension (4.7\% [3.5-6.4]) and solid tumours (3.9\% [2.8-5.4]). Inflammatory bowel disorders (IBD; namely Crohn's disease and ulcerative colitis), hypertension, atrial fibrillation and depressive disorders were more frequent in patients with SpA compared to controls (Figure 2).

\subsection{Resource consumption}

In 2012, only 143 (17.3\%) of the 827 patients with SpA had been dispensed a csDMARD and $212(25.6 \%)$ a bDMARD; for 51 patients (6.2\%), no specific treatment for SpA had been dispensed (Table 2). Most patients on bDMARD were dispensed a single agent $(N=196$; 92.5\%), fifteen patients two agents and one patient three agents. The most frequently dispensed agents were etanercept $(N=97 ; 45.8 \%)$, adalimumab $(N=77 ; 36.3 \%)$ and infliximab ( $N=44 ; 20.8 \%$ ). Other bDMARDs were golimumab (four patients), tocilizumab 
(two patients) and certolizumab pegol, abatacept and rituximab (one patient each). The patient using rituximab also had a cancer diagnosis.

\subsection{Cost valuation}

The total annual mean per capita spending for healthcare in patients with SpA in 2012 was $€ 6,122$ [95\% Cl: $€ 5,838-€ 6,406]$. The most expensive items of expenditure were medication (€2,755 [€2,586-€2,924]) and hospitalisation (€1,764 [€1,594-€1,934]), comprising in similar parts of overnight hospital stays, outpatient visits and injection sessions. In the matched control group, total annual mean per capita spending was $€ 1,682[€ 1,566-$ $€ 1,798]$. The total cost specifically attributable to SpA corresponds to the difference between the mean per capita spending in the SpA and control groups, namely $€ 4,440$ $[€ 4,040-€ 4,840]$. Extrapolating this per capita cost to the projected total number of 87,979 individuals with severe SpA in France, the total annual cost to national health insurance attributable to severe SpA in 2012 can be estimated at €391 [€355-€426] million. Over half of this difference was accounted for by medication costs. Other items of healthcare expenditure contributing to the incremental cost of SpA by over $10 \%$ were hospital outpatient visits (16.9\%) and injection sessions (16.5\%) (Table 3).

\section{Discussion}

This study provides data on the prevalence and incidence of severe forms of SpA in France. Overall, 827 patients with severe SpA were identified in the EGB database in 2012, corresponding to an adjusted prevalence rate of $0.18 \%$ in the adult population. Extrapolating this to the entire French adult population corresponds to an estimated 87,979 severe SpA cases in 2012. When comparing patients with severe SpA to a matched control population, a number of comorbidities (including severe hypertension, atrial fibrillation and depression) 
appeared to be overrepresented in the former group. Moreover, the mean per capita healthcare expenditure was 3.6-fold higher in severe SpA patients than in controls. Collectively, these data indicate that severe SpA has a substantial burden both on patients and the French healthcare system.

The prevalence derived in this study is around half that reported in two previous French surveys, performed in $2001(0.30 \%$ [0.17-0.46]) (5) and in $2010(0.43 \%$ [0.26\%$0.70 \%])(6)$, which considered all cases of SpA, regardless of severity. The adjusted incidence rate was estimated at 1.4 cases per 10,000 persons per year. The mean age of incident cases was 42.7 years, which is higher than previous reports for SpA age of onset (31), suggesting that many years may elapse between first symptoms and qualification for ALD status.

The prevalence of axial SpA has historically been considered to be higher in men (4), although not all studies have identified such a difference $(4,5)$. In our study, prevalence rates were similar between genders, with the exception of those aged over fifty-five, where prevalence rates were lower in women. The sharp decline observed in women was unexpected for a chronic disease such as severe SpA, which is neither self-limiting, nor associated with reduced survival. Possible explanations for this observation include potential systematic bias inherent to the study; for example, it is possible that the oldest women could have less active disease, and thus be less likely to qualify for ALD status and be identified in this study. It is also possible that diagnosis of SpA in women has improved due to better awareness of the medical community, leading to greater accrual of women with ALD status for $\mathrm{SpA}$ in recent decades. Alternatively, such a gender-dependent prevalence shift could be real and correspond to a systematic change in a predisposing environmental factor appearing in the 1960s, such as smoking or use of the contraceptive pill. 
One of the major findings of our study was the high rate of comorbidity with other severe diseases; almost one third of patients with severe SpA $(28.9 \%)$ also presented with ALD status for an extra-articular manifestation or comorbidity. The observed frequency of IBD was close to that reported in the validation study of the ASAS classification criteria $(3.4 \%)(2)$, and higher than in the control population. In addition, an elevated comorbidity rate was observed for diseases for which the association with SpA is less well characterised: notably hypertension, atrial fibrillation and other arrhythmias, and depression.

An elevated frequency of cardiovascular diseases and hypertension in patients with SpA has been reported in a number of previous studies, although the findings are inconsistent and this association remains controversial (7, 9, 11, 32, 33). A meta-analysis investigating cardiovascular disease risk in patients with SpA, updated in 2014 (32, 34), reported an elevated risk of acute myocardial infarction and stroke; however, the incidence of hypertension was not evaluated. Given the limited number of observed cases (18 IHD and 7 strokes), our study was underpowered to detect an increased risk of these conditions and ALD status analysis may underestimate their true incidence and introduce bias. Demonstrating an increased risk of hypertension, which is both more frequent and itself a risk factor for IHD and stroke, may be more feasible in relatively small cohorts such as ours. One potential explanation for the elevated risk of hypertension in our study could be longterm use of NSAIDs, which are known to increase blood pressure and contribute to elevated cardiovascular risk in SpA patients $(35,11)$.

An association between cardiac conduction disorders (such as atrial fibrillation and other arrhythmias) and SpA was postulated over thirty years ago $(36,37)$, but very little information has become available since. High rates of conduction disorders and abnormalities have been reported in ankylosing spondylitis patients compared to matched 
and unmatched control groups $(38,39)$. Whether such findings could contribute to an increased risk of arrhythmias, as observed in our study, remains to be determined. Again, use of NSAIDs may be a confounding factor $(40,41)$.

The higher frequency of severe depression in patients with SpA compared to the matched controls corroborates the findings of a few earlier studies: in an exhaustive regional patient registry in the Netherlands (29), an elevated risk of depression in ankylosing spondylitis patients was observed with a RR of 1.63. Other studies have also reported a high level of depressive symptoms in patients with SpA (28) and correlation between disease activity measured with the BASDAI and severity of depressive symptoms (42).

Certain disorders previously reported to be more frequent in patients with $\mathrm{SpA}$, such as osteoporosis (6), could not be identified in our study since they do not qualify for ALD status. In agreement with previous studies (7), we failed to observe any increase in mortality risk in patients with SpA. However, this result should be taken with caution, as the study was not powered to detect modest mortality differences.

Due to the impossibility of directly attributing any item of medical consumption to SpA (except hospitalisation), the fraction of medical expenditure attributable to SpA was estimated though a case-control analysis. The mean per capita direct medical cost attributable to SpA was $€ 4,440$, corresponding to an estimated total annual cost to national health insurance of $€ 391$ million. This cost can be compared to a per capita cost of rheumatoid arthritis (RA) in France in $2010(€ 3,308)$, which was derived from the EGB database and established using an identical approach (43). A higher per capita cost of SpA compared to RA has also been reported recently in a direct comparative cohort study from Korea (44), although previous indirect comparisons had suggested the opposite (45). Due to the limitations of the database it was not possible to confirm which proportion of the costs 
attributable to SpA in this analysis were truly linked to the disease itself and which arose from extra-articular manifestations or co-morbidities over-represented in this patient population.

Our data can be compared with a French micro-costing study of patients with early SpA enrolled in the DEvenir des Spondyloarthrites Indifférenciées Récentes (DESIR) cohort between 2007 and 2010, which reported direct medical costs of $€ 5,004$ in the year following inclusion into the cohort and $€ 4,961$ in the third year (18), and took into account costs reimbursed by payers other than national health insurance providers. Another micro-costing study, investigating the healthcare resource utilisation of patients entering a clinical trial of infliximab, reported a mean per capita direct medical cost of $€ 2,912$ in the year preceding infliximab treatment, which rose to $€ 20,000$ after treatment began (19). Comparison of costing studies between countries is problematic due to differences in healthcare funding, as well as differences in data sources. Nonetheless, the findings of our study are of similar magnitude to per capita direct medical costs reported by other European cost-of-illness studies of patients with SpA: a German study reported costs of $€ 3,676$ during 2002 (46) and a Welsh study costs of $£ 3,230(\sim € 3,875)$ in 2010 (47).

The limitations of this study are principally those inherent to studies of claims databases. For example, it was not possible to ascertain the diagnosis of SpA through patient records, in contrast with the two earlier French studies $(5,6)$. However, given that physicians are required to document a diagnosis of severe SpA when applying for ALD status, the risk of misdiagnosis is probably low (though few studies have performed a direct comparison between ALD status and patients' clinical records, and to our knowledge none have done this for SpA). The overall frequency of extra-articular manifestations and comorbidities is underestimated, since these were only documented if their severity qualified for ALD status. 
Despite these limitations, the EGB database represents a useful tool for documenting patients with relatively infrequent diseases such as SpA, since it is fully representative of health insurance beneficiaries in France and the information can be generalised to the total population with minimal risk of bias - our study was based on 827 identified cases of SpA compared to 29 and 32 cases in the previous French surveys $(5,6)$.

In conclusion, this nationwide database analysis provides data on the prevalence and cost of severe SpA in France, and allowed us to document several severe comorbidities that appear to be frequently associated with this disease. The results suggest that the presence of cardiovascular disorders, notably hypertension, as well as depression, should be assessed systematically in patients with $\mathrm{SpA}$ in order to ensure optimal standards of care.

\section{Acknowledgements}

The authors acknowledge Susanne Wiegratz (UCB Pharma GmbH, Monheim am Rhein, Germany) for publication coordination, and Maria Haughton (Costello Medical, Cambridge, UK) for editorial assistance in preparing this manuscript for publication.

\section{Disclosures}

P.C. is a speaker, consultant or investigator for AbbVie, BMS, Celgene, Janssen, Lilly, MSD, Novartis, Pfizer, Roche and UCB Pharma; F.F. and C.L. are consultants for UCB Pharma; G.C. and J.-M.J. are employees of UCB Pharma; T.D.C. was an employee of UCB Pharma during manuscript development; J.G. has no conflicts of interest to declare; M.B. acted as a consultant for UCB Pharma and Novartis, and received an investigational grant from MSD. 


\section{References}

1. Baeten D, Breban M, Lories R, Schett $G$, Sieper J. Are spondylarthritides related but distinct conditions or a single disease with a heterogeneous phenotype? Arthritis Rheum 2013;65:12-20.

2. Rudwaleit $M$, van der Heijde $D$, Landewe $R$, et al.The Assessment of SpondyloArthritis International Society classification criteria for peripheral spondyloarthritis and for spondyloarthritis in general. Ann Rheum Dis 2011;70:25-31.

3. Sieper J, Rudwaleit M, Baraliakos X, et al. The Assessment of SpondyloArthritis international Society (ASAS) handbook: a guide to assess spondyloarthritis. Ann Rheum Dis 2009;68:ii1-44.

4. Stolwijk C, van Onna M, Boonen A, van Tubergen A. Global prevalence of spondyloarthritis: A systematic review and meta-regression analysis. Arthritis Care Res (Hoboken) 2015;68:1320-31.

5. Saraux A, Guillemin F, Guggenbuhl P, et al. Prevalence of spondyloarthropathies in France: 2001. Ann Rheum Dis 2005;64:1431-5.

6. Costantino F, Talpin A, Said-Nahal R, et al. Prevalence of spondyloarthritis in reference to HLA-B27 in the French population: results of the GAZEL cohort. Ann Rheum Dis 2015;74:689-93.

7. Molto A, Etcheto A, van der Heijde D, et al. Prevalence of comorbidities and evaluation of their screening in spondyloarthritis: results of the international cross-sectional ASAS-COMOSPA study. Ann Rheum Dis 2016;75:1016-23.

8. Prati C, Claudepierre P, Pham T, Wendling D. Mortality in spondylarthritis. Joint Bone Spine 2011;78:466-70.

9. Bremander A, Petersson IF, Bergman S, Englund M. Population-based estimates of common comorbidities and cardiovascular disease in ankylosing spondylitis. Arthritis Care Res (Hoboken) 2011;63:550-6.

10. Gladman DD, Ang M, Su L, Tom BD, Schentag CT, Farewell VT. Cardiovascular morbidity in psoriatic arthritis. Ann Rheum Dis 2009;68:1131-5.

11. Essers I, Stolwijk C, Boonen A, et al. Ankylosing spondylitis and risk of ischaemic heart disease: a population-based cohort study. Ann Rheum Dis 2016;75:203-9.

12. Palla I, Trieste L, Tani C, et al. A systematic literature review of the economic impact of ankylosing spondylitis. Clin Exp Rheumatol 2012;30:S136-41.

13. Reveille JD, Ximenes A, Ward MM. Economic considerations of the treatment of ankylosing spondylitis. Am J Med Sci 2012;343:371-4. 
14. Boonen A, van der Heijde D, Landewe R, et al. Costs of ankylosing spondylitis in three European countries: the patient's perspective. Ann Rheum Dis 2003;62:741-7.

15. Boonen $A$, van der Heijde $D$, Landewé $R$, et al. Direct costs of ankylosing spondylitis and its determinants: an analysis among three European countries. Ann Rheum Dis 2003;62:732-40.

16. Boonen A, Severens JL. Ankylosing spondylitis: what is the cost to society, and can it be reduced? Clin Rheumatol 2002;16:691-705.

17. Ward MM. Functional disability predicts total costs in patients with ankylosing spondylitis. Arthritis Rheum 2002;46:223-31.

18. Harvard S, Guh D, Bansback N, et al. Costs of early spondyloarthritis: estimates from the first 3 years of the DESIR cohort. RMD Open 2016;2:e000230.

19. Fautrel B, Benhamou M, Breban M, et al. Cost effectiveness of two therapeutic regimens of infliximab in ankylosing spondylitis: economic evaluation within a randomised controlled trial. Ann Rheum Dis 2010;69:424-7.

20. Moulis G, Lapeyre-Mestre M, Palmaro A, Pugnet G, Montastruc JL, Sailler L. French health insurance databases: What interest for medical research? Rev Med Interne 2015;36:411-7.

21. Tuppin $P$, de Roquefeuil $L$, Weill $A$, Ricordeau $P$, Merlière $Y$. French national health insurance information system and the permanent beneficiaries sample. Rev Epidemiol Santé Publique 2010;54:286-90.

22. World Health Organization. International Classification of Diseases - 10th revision. Geneva: WHO; 1990. Available at:

http://apps.who.int/classifications/icd10/browse/2016/en [Last accessed: 19 February 2018].

23. Haute Autorité de Santé. Guide Affection de longue durée : spondylarthrite grave. St Denis; 2008. Available at: https://www.hassante.fr/portail/upload/docs/application/pdf/201001/ald_27_gm_spondylarthrite_web.pdf [Last accessed: 19 February 2018].

24. Institut national de la statistique et des études économiques. Base chiffres clés : évolution et structure de la population 2012 Paris: INSEE; 2012 [Available from: http://www.insee.fr/fr/themes/detail.asp?reg_id=99\&ref_id=base-cc-evol-struct-pop2012].

25. Brakenhoff LK, van der Heijde DM, Hommes DW, Huizinga TW, Fidder HH. The joint-gut axis in inflammatory bowel diseases. J Crohns Colitis 2010;4:257-68. 
26. Karreman MC, Luime JJ, Hazes JM, Weel AE. The prevalence and incidence of axial and peripheral spondyloarthritis in inflammatory bowel disease: a systematic review and meta-analysis. J Crohns Colitis 2017;11:631-42.

27. Chen $\mathrm{HH}$, Yeh SY, Chen HY, Lin $\mathrm{CL}$, Sung FC, Kao CH. Ankylosing spondylitis and other inflammatory spondyloarthritis increase the risk of developing type 2 diabetes in an Asian population. Rheumatol Int 2014;34:265-70.

28. Barlow JH, Macey SJ, Struthers GR. Gender, depression, and ankylosing spondylitis. Arthritis Care Res 1993;6:45-51.

29. Meesters JJ, Bremander A, Bergman S, Petersson IF, Turkiewicz A, Englund M. The risk for depression in patients with ankylosing spondylitis: a population-based cohort study. Arthritis Res Ther 2014;16:418.

30. Sun LM, Muo CH, Liang JA, Chang SN, Sung FC, Kao CH. Increased risk of cancer for patients with ankylosing spondylitis: a nationwide population-based retrospective cohort study. Scand J Rheumatol 2014;43:301-6.

31. Giovannini L, Orlandi M, Lodato C, et al. One year in review 2015: spondyloarthritis. Clin Exp Rheumatol 2015;33:769-78.

32. Mathieu S, Gossec L, Dougados M, Soubrier M. Cardiovascular profile in ankylosing spondylitis: a systematic review and meta-analysis. Arthritis Care Res (Hoboken) 2011;63:557-63.

33. Haroon NN, Paterson JM, Li P, Inman RD, Haroon N. Patients with ankylosing spondylitis have increased cardiovascular and cerebrovascular mortality: a populationbased study. Ann Intern Med 2015;163:409-16.

34. Mathieu S, Pereira B, Soubrier M. Cardiovascular events in ankylosing spondylitis: an updated meta-analysis. Semin Arthritis Rheum 2015;44:551-5.

35. Snowden S, Nelson R. The effects of nonsteroidal anti-inflammatory drugs on blood pressure in hypertensive patients. Cardiol Rev 2011;19:184-91.

36. Bergfeldt L, Edhag $\mathrm{O}$, Vallin $\mathrm{H}$. Cardiac conduction disturbances, an underestimated manifestation in ankylosing spondylitis. A 25-year follow-up study of 68 patients. Acta Med Scand 1982;212:217-23.

37. Nitter-Hauge S, Otterstad JE. Characteristics of atrioventricular conduction disturbances in ankylosing spondylitis (Mb. Bechterew). Acta Med Scand 1981;210:197-200.

38. Brunner F, Kunz A, Weber U, Kissling R. Ankylosing spondylitis and heart abnormalities: do cardiac conduction disorders, valve regurgitation and diastolic dysfunction occur 
more often in male patients with diagnosed ankylosing spondylitis for over 15 years than in the normal population? Clin Rheumatol 2006;25:24-9.

39. Acar G, Sayarlioglu M, Akcay A, et al. Assessment of atrial electromechanical coupling characteristics in patients with ankylosing spondylitis. Echocardiography 2009;26:54957.

40. Schmidt $M$, Lamberts $M$, Olsen AM, et al. Cardiovascular safety of non-aspirin nonsteroidal anti-inflammatory drugs: review and position paper by the working group for Cardiovascular Pharmacotherapy of the European Society of Cardiology. Eur Heart J 2016;37:1015-23.

41. Liu G, Yan YP, Zheng XX, et al. Meta-analysis of nonsteroidal anti-inflammatory drug use and risk of atrial fibrillation. Am J Cardiol 2014;114:1523-9.

42. Martindale J, Smith J, Sutton CJ, Grennan D, Goodacre L, Goodacre JA. Disease and psychological status in ankylosing spondylitis. Rheumatology (Oxford) 2006;45:128893.

43. Fautrel B, Cukierman G, Joubert JM, Laurendeau C, Gourmelen J, Fagnani F. Healthcare service utilisation costs attributable to rheumatoid arthritis in France: Analysis of a representative national claims database. Joint Bone Spine 2016;83:53-6.

44. Lee TJ, Park BH, Kim JW, Shin K, Lee EB, Song YW. Cost-of-illness and quality of life in patients with ankylosing spondylitis at a tertiary hospital in Korea. J Korean Med Sci 2014;29:190-7.

45. Franke LC, Ament AJ, van de Laar MA, Boonen A, Severens JL. Cost-of-illness of rheumatoid arthritis and ankylosing spondylitis. Clin Exp Rheumatol2009; 27:S118-23.

46. Huscher D, Merkesdal S, Thiele K, Zeidler H, Schneider M, Zink A. Cost of illness in rheumatoid arthritis, ankylosing spondylitis, psoriatic arthritis and systemic lupus erythematosus in Germany. Ann Rheum Dis 2006;65:1175-83.

47. Cooksey R, Husain MJ, Brophy S, et al. The cost of ankylosing spondylitis in the UK using linked routine and patient-reported survey data. PLoS One 2015;10:e0126105. 
Table 1. Criteria for severe spondyloarthritis offering eligibility for full coverage of medical expenses (ALD status) (23).

1. Presence of an obviously severe presentation:

- EITHER destructive arthritis, and particularly coxitis

- OR severe SpA-associated extra-articular pathology:

○ Chronic intestinal disease

○ Repetitive uveitis

- Cardiac involvement (aortic or mitral valve disease, myocardiopathy, pericarditis, atrioventricular bloc).

OR 2. Presence of active disease manifestations in spite of use of NSAIDs at the highest recommended or tolerated dose (at least two flares at three-monthly intervals):

- Involving three or more simultaneously affected joints

- Flares with a BASDAl score $>4$

- Marked functional impairment with a BASFI score $>4$

OR 3. Need for daily NSAIDs at the highest recommended or tolerated dose in order to control symptoms

Criteria published by French health authorities. SpA: spondyloarthritis; NSAID: non-steroidal anti-inflammatory disease; BASDAI: Bath Ankylosing Spondylitis Disease Activity Index; BASFI: Bath Ankylosing Spondylitis Functional Index. 
Table 2. Healthcare resource consumption in patients with SpA over 12 months in 2012.

\begin{tabular}{|c|c|}
\hline & $N=827$ \\
\hline \multicolumn{2}{|l|}{ Consultations in community care } \\
\hline General practitioner consultation & $714(86.3 \%)$ \\
\hline Rheumatologist consultation & $267(32.3 \%)$ \\
\hline Other specialist consultation & $626(75.7 \%)$ \\
\hline \multicolumn{2}{|l|}{ Hospital visits } \\
\hline $\begin{array}{l}\text { Hospital outpatient visits (including injection } \\
\text { sessions) }\end{array}$ & $432(52.2 \%)$ \\
\hline Emergency room visits & $105(12.7 \%)$ \\
\hline Hospital stay & $222(26.8 \%)$ \\
\hline Hospital stay for SpA & $98(11.9 \%)$ \\
\hline \multicolumn{2}{|l|}{ Medication } \\
\hline \multicolumn{2}{|l|}{ Symptomatic treatments } \\
\hline Analgesics & $656(79.3 \%)$ \\
\hline Myorelaxants & $50(6 \%)$ \\
\hline NSAIDS & $523(63.2 \%)$ \\
\hline Glucocorticoids & $189(22.9 \%)$ \\
\hline Biphosphonates & $21(2.5 \%)$ \\
\hline Synthetic DMARDs & $143(17.3 \%)$ \\
\hline bDMARDs & $212(25.6 \%)$ \\
\hline No specific SpA treatment & $51(6.2 \%)$ \\
\hline
\end{tabular}

Data are presented as the number of patients (\%) using each individual resource. All resource categories, including medication, are non-exclusive. 
Table 3. Annual per capita healthcare costs in patients with $\mathrm{SpA}$ and a matched control group.

\begin{tabular}{|c|c|c|c|c|}
\hline & SpA patients & Controls & & \\
\hline & $N=827$ & $N=2481$ & {$[95 \% \mathrm{Cl}]$} & $\%$ \\
\hline Community care costs & $4358 \pm 6029$ & $955 \pm 2915$ & 3403 [2976;3830] & $76.6 \%$ \\
\hline Physician consultations & $416 \pm 439$ & $194 \pm 357$ & $222[189 ; 255]$ & $5.0 \%$ \\
\hline General practitioners & $168 \pm 185$ & $75 \pm 102$ & $93[80 ; 106]$ & $2.1 \%$ \\
\hline Rheumatologists & $38 \pm 63$ & $3 \pm 18$ & $35[31 ; 39]$ & $0.8 \%$ \\
\hline Other specialists & $209 \pm 330$ & $116 \pm 311$ & $93[67 ; 119]$ & $2.1 \%$ \\
\hline \multicolumn{5}{|l|}{ Other healthcare } \\
\hline professionals & $729 \pm 1957$ & $234 \pm 1333$ & $495[352 ; 638]$ & $11.1 \%$ \\
\hline Dental care & $59 \pm 136$ & $45 \pm 122$ & $14[4 ; 24]$ & $0.3 \%$ \\
\hline Nurse & $95 \pm 742$ & $52 \pm 579$ & $43[-12 ; 98]$ & $1.0 \%$ \\
\hline Physiotherapists & $235 \pm 543$ & $41 \pm 231$ & $194[156 ; 232]$ & $4.4 \%$ \\
\hline Others & $340 \pm 1658$ & $96 \pm 1227$ & $244[121 ; 367]$ & $5.5 \%$ \\
\hline Medication & $2755 \pm 4848$ & $365 \pm 1906$ & $2390[2051 ; 2729]$ & $53.8 \%$ \\
\hline Medical devices & $151 \pm 1540$ & $71 \pm 493$ & $80[-27 ; 187]$ & $1.8 \%$ \\
\hline Biological testing & $139 \pm 168$ & $50 \pm 121$ & $89[77 ; 101]$ & $2.0 \%$ \\
\hline Transportation & $150 \pm 578$ & $39 \pm 353$ & $111[69 ; 153]$ & $2.5 \%$ \\
\hline Other community care & $19 \pm 117$ & $1 \pm 22$ & $18[10 ; 26]$ & $0.4 \%$ \\
\hline
\end{tabular}


costs

\begin{tabular}{|c|c|c|c|c|}
\hline Hospitalization costs & $1764 \pm 4886$ & $726 \pm 3982$ & $1038[670 ; 1406]$ & $23.4 \%$ \\
\hline Overnight stays & $827 \pm 3473$ & $540 \pm 3368$ & $287[16 ; 558]$ & $6.5 \%$ \\
\hline Day hospitalizations & $937 \pm 3251$ & $186 \pm 1391$ & $751[523 ; 979]$ & $16.9 \%$ \\
\hline Injection sessions & $732 \pm 3325$ & 0 & $732[505 ; 959]$ & $16.5 \%$ \\
\hline Total & $6,122 \pm 8179$ & $1,682 \pm 5769$ & $4440[3838 ; 5042]$ & $100 \%$ \\
\hline
\end{tabular}




\section{FIGURE LEGENDS}

Figure 1. Prevalence of ALD status for severe SpA by age and gender in 2012.

Prevalence rates are presented with their $95 \%$ confidence limits. The numbers above the symbols represent the probability values for a difference in prevalence between women and men.

Figure 2. Relative frequency of comorbidities in patients with ALD status for severe SpA versus controls

Cases (patients with ALD status for severe SpA) compared to a reference group of controls frequency-matched using age and gender sub-groups. Data are presented as odds ratios with their $95 \% \mathrm{Cl}$. The diseases studied are presented with their corresponding ICD-10 disease codes. AF: atrial fibrillation. 


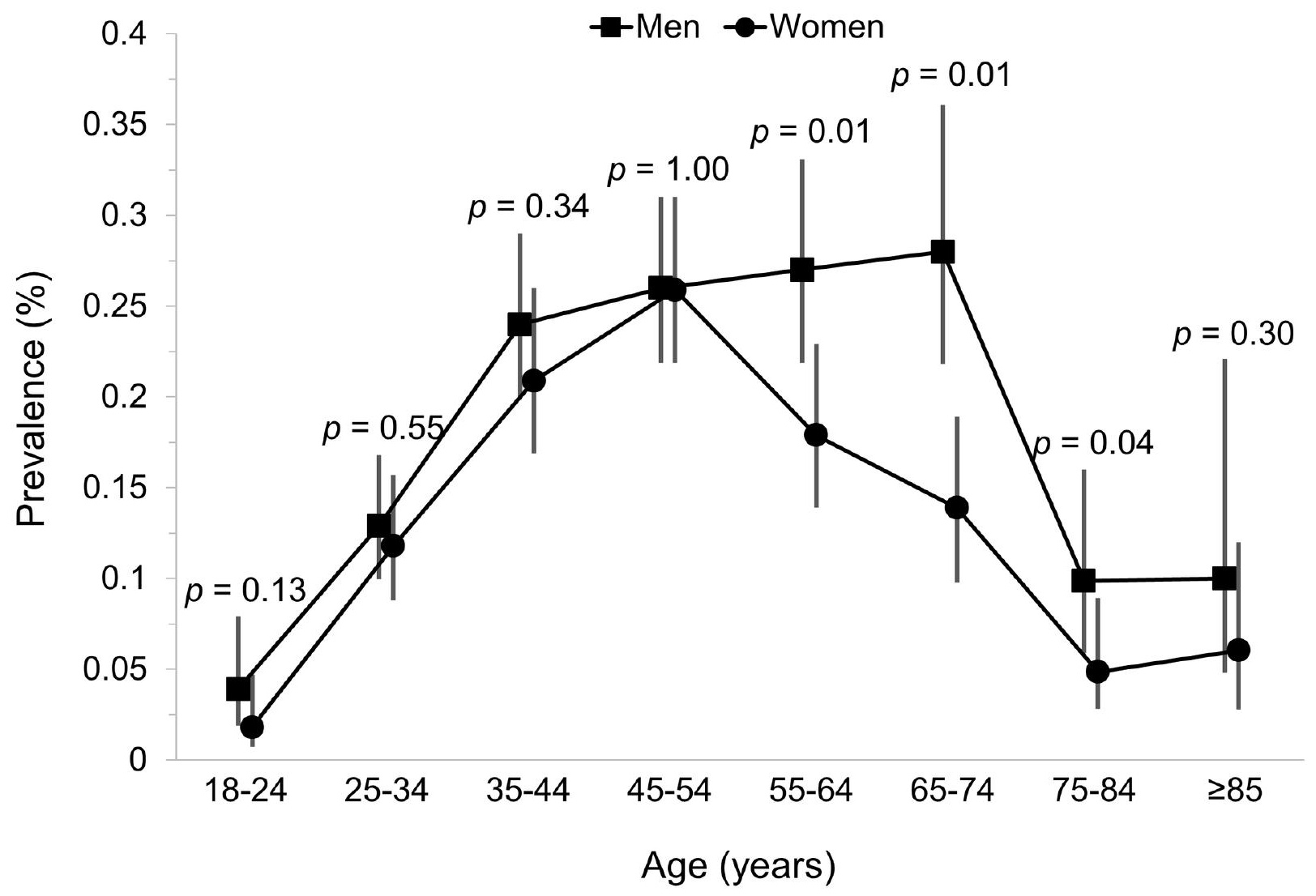




\section{Disease (ICD-10 code)}

\section{Diabetes mellitus (E10, E11)}

Stroke $(163,164,169)$

Hypertension (I10)

Ischemic heart disease (I25)

AF/Arrhythmias (148, 149)

Atherosclerosis (170)

Solid tumors (C00-C80)

Hematological malignancies (C82-C85, C90-C96)

Depressive disorders (F31-F33, F60)

Inflammatory bowel disorders (K50, K51)
OR [95\% Cl]; p-value

\section{N2 control}

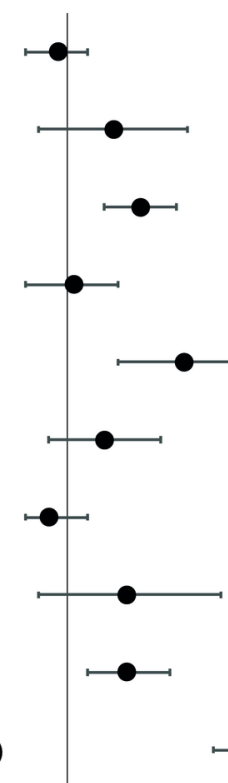

$0.9[0.6-1.3] ; p=0.59$

$1.8[0.7-4.5] ; p=0.0008$

$2.5[1.6-3.9] ; p=<0.0001$

$1.1[0.6-1.9] ; p=0.67$

$4.3[1.9-9.6] ; p=<0.0001$

$1.6[0.8-3.2] ; p=0.20$

$0.8[0.6-1.3] ; p=0.43$

$2.1[0.7-6.8] ; p=0.18$

$2.1[1.3-3.6] ; p=0.003$

15.0 [6.2-36.2]; $p=<0.0001$
41

7

37

18

14

12

32

5

26
37

135

12

45

48

10

23

112

7

6 